\title{
A Study on the Construction of Layered Teaching and Training Mode of Basketball in Colleges and Universities
}

\author{
Zhi Liu \\ University of Electronic Science and Technology of China, Chengdu City, \\ Sichuan Province, 611731, China
}

\begin{abstract}
In the current context that the knowledge serves the social development, the state has paid more and more attention to the cultivation of the comprehensive quality and practical ability of the talents. The continuous optimization and perfection in teaching methods and process are important means to improve students' comprehensive practical ability and to promote their full development in physical and mental health. The basketball teaching is a major content of physical education. The construction of its teaching methods and modes has important significance for the realization of physical education objectives. In view of this, the related analysis is conducted in this paper mainly on the construction of layered teaching and training mode of basketball in colleges, which is only for reference.

Keywords: college basketball; layered teaching; training mode; construction and exploration
\end{abstract}

\section{The Important Significance of Layered Teaching and Training Mode Construction of College Basketball}

1.1 Promote the comprehensive and all-round development of college students' basketball quality

In the process of practical teaching of college basketball, layered teaching can effectively promote students' individualized developmental differences, and 
targeted teaching can be conducted according to the students' different personality and characteristics differences, which can better meet the individualized demands of students' learning. In this layered teaching mode, students can experience targeted training, which can effectively improve the teaching efficiency and quality. In the process of teaching, the exchange between teachers and students become more frequent and effective. Students can specifically put forward technical problems and weakness in theoretical knowledge so that they can get effective access to teachers' help, which can also promote a good teaching atmosphere. This mode is more meaningful than the traditional passive theoretical teaching of students. Therefore, layered teaching can not only effectively meet the needs of students' personalized teaching, but also better meet the development demand of college basketball quality[1]

\subsection{Perfect the reform of college basketball}

It is not difficult to find that colleges only give students an effective training in professional basketball skills, but lack adequate attention to the health of students in the traditional teaching process, which will result in the lack of effectiveness and interest of college basketball classes. Students cannot get the fun from basketball in the learning process, and their basketball skills are difficult to improve. In the layered teaching mode, college basketball classes not only cannot effectively avoid the only effective training for professional skills and tactics, but also can bring more evaluation indicators into the teaching objectives in the teaching process, and set students' basketball interest as the key education content. Under this concept, the college basketball classes can be more harmonious, the relationship between teachers and students can be effectively promoted, and thus continuously promote the effective penetration and improvement of teaching methods and modes.

\subsection{Promote the comprehensive and balanced development of students' basketball professional level}

In the process of teaching practice, because students are subjected to factors of personal conditions, there are large layered phenomenon in students' mastery condition, understanding condition and absorption ability of basketball skills. When many students come out of the school gate after the completion of basketball-learning, although they have learned basketball, the skill is still at low level, which brings great trouble and obstacles to the students' balanced development of basketball ability[2]. Therefore, the layered construction of college basketball can effectively achieve the students' individual need and development. In the layered teaching mode, students' interpersonal skills and team awareness can be effectively carried out. The students can study more happily under the same attention, and the phenomenon of lagging behind can be effectively avoided, which ensures the balanced development of overall basketball level. 


\section{Strategies and Measures for the Construction of Layered Basketball Teaching and Training Mode in Colleges}

\subsection{Effective stratification for college basketball teaching objectives}

In order to construct a good layered teaching and training mode, we must first effectively stratify the teaching objectives, namely the students' teaching goals are effectively designed according to their actual basketball levels. The whole teaching objectives can be better for all the students, and give consideration to both ends. The comprehensive improvement and training are performed on students' enthusiasm, cognitive skills and motor skills on the basis of full consideration of exam outline and teaching standards. Different levels of teaching objectives are chose according to the characteristics of basketball teaching and requirements of teaching knowledge.

For example, teachers can establish the following teaching objectives for different levels of students. For those students who are poor in basketball skills, teachers should be able to recognize that this part of the students lack basketball enthusiasm, and some students may even have a huge basketball psychological barrier[3]. Therefore, for such students, teachers should set the development of their basketball interests and basic basketball skills and levels as teaching objectives. For this purpose, teachers should design a number of game sessions in the teaching process so that the students can effectively cultivate the students' basketball enthusiasm, and effectively help students to establish their confidence in basketball.

\subsection{Effective stratification of the basketball teaching main body in colleges}

As we all know, students are the main body of college basketball teaching. Therefore, we should carry out layered teaching. First, we should stratify students effectively. According to the different students' differences in types and abilities, the scientific and rational stratification for the guiding principle of college basketball teaching main body should be conducted to ensure the objectivity and effectiveness of students' teaching. In the process of stratifying students, we should use a variety of comprehensive investigation targets as the evaluation indicators. Students' level of steering movement, the love degree of basketball and their basic quality of basketball should be considered as stratified reference coefficient. Besides, and the scientific proportion should be determined to ensure the improvement of the students' physical quality, in which the quality of endurance and power is particularly important[4].

For example, in the stratification of the students, the teachers can use the steering evaluation method to evaluate male students by 1000 meters race and female students by 800 meters race, as well as push-ups and so on. The scientific rating scale should be set. The scientific division of the scores can be set as follows. The scores of more than 85 points can be identified as excellent. The scores from 75 to 85 points are divided into good grades. The scores below 60 points are divided into a lower qualification level. Then targeted stratification of students' individual 
differences in the physical quality can be realized so that we can build a more stratified health care courses for them.

\subsection{Reasonable stratification of evaluation system of basketball course in colleges}

In the process of practical teaching, we should regard health as the main teaching content, regard students as the educational main body, conduct targeted evaluation on students' learning effect, set up sound evaluation indices and points standard according to the assessment content, and then build a reasonable layered evaluation system to effectively ensure that students participate in the basketball classroom, the students basketball skills are correlated with the theoretical knowledge, and the unity and cooperation ability is brought into the evaluation system in the process of basketball education, which can effectively break the shortcomings of traditional educational mode with the focus on skills and the ignorance of students' learning interest and physical and mental health. Besides, more effective guarantee, to a certain extent, can be given on students' basketball learning enthusiasm and interest[5]. In the process of different levels division of evaluation system in the basketball classes, we should take the actual needs of college students as an important reference, comprehensively evaluate students' basketball skills and theoretical knowledge, continuously strengthen students' participation in basketball, and improve students' learning attitude and team spirit. In this manner, the diversity and rationality of teaching evaluation indicators can be effectively reflected.

In the process of evaluating students' basketball skills and theoretical knowledge, based on the method of percentile system, the teachers can effectively combine the qualitative and quantitative methods via taking the basketball teaching characteristics into account, guide students to conduct good self-evaluation and mutual assessment according to the actual teaching needs, students' learning needs and the actual conditions, complete student's basketball skills evaluation system, optimize student's skills and technology assessment records, and then improve the comprehensive evaluation of the overall teaching through this method. This manner can effectively strengthen students' enthusiasm in the process of learning, make students fully aware of the importance of learning basketball, and achieve the layered evaluation on the teaching process and effectiveness. For example, we can proportionally integrate the basketball assessment indictors in every semester, and consider the whole basketball scores as the sum of several parts.

\subsection{Reasonable stratification of feedback system of college basketball class}

In the actual teaching process, we should continuously improve and perfect teaching on the original teaching basis, and establish a sound curriculum feedback system. Through the construction of feedback system of basketball classes, teachers can effectively know students' knowledge mastery. Through this feedback, a good teaching cycle can be achieved, and then a more targeted teaching objectives design and improvement can be given to the students [6]. In 
the process of communication with students, teachers need to have patience, conduct layered object detection according to students' different layered teaching means, set up different levels of goals for students with various mastery degree, and solve students' problems and obstacles in sports teaching process in a targeted way. At the same time, the sense of responsibility and the learning mode of solidarity and helping each other need to be strengthened in the process of teaching. The ability of students need to be further expanded and strengthened in the exchange. Meanwhile, we should ensure the students' physical and mental health, continuously improve their learning ability and level, and then continuously enhance their professional skills of basketball and achieve the ultimate goal of physical education.

\section{Conclusion}

College basketball teaching is an important part of college teaching, which is of great significance to promote students' comprehensive quality and physical and mental health. Therefore, teachers should pay more attention to it, and continuously improve and perfect teaching methods and modes. Adopting the layered teaching mode in colleges can better infuse people-centered ideas into the teaching process, and make students better feel the fun of study in the learning process. However, in practice, many problems and obstacles could been encountered, which requires the educators to timely discover problems, raise problems and effectively solve problems in the course of practice so as to realize the ultimate goal of education.

\section{Acknowledgements}

The research work was supported by Humanities and social science in Sichuan Province department of education (PE) social science research base project "study on the development of sports tourism resources of Sichuan Province(TY2016214).

\section{References}

[1] KAN Jie. Study on the construction of layered teaching and training mode of basketball in colleges. Sports, (11), pp.102-103, 2016.

[2] LIU Gang. Application of layered teaching in college basketball teaching. Contemporary Sports Science and Technology, (16), pp.108-109, 2015.

[3] WEN Xizhuang. Practice of layered teaching mode in college basketball selective courses. Journal of Liaodong University (Natural Science), (04), pp.291-293, 2013. 
[4] LI Shaolan, CHEN Qiaomin. Study on the effects of basketball layered teaching on the physical qualities of junior middle school boys and basketball skills. Journal of Nanchang Education College, (09), pp.190-191, 2011.

[5] XIE Bing. The application of layered teaching method in college basketball teaching. Sports, (02), pp.84-85, 2011.

[6] WU Huahui, CUI Haiying. On the idea of the implement of layered teaching in college basketball teaching. Journal of Harbin Physical Education Institute, (06), pp.56-57, 2005. 